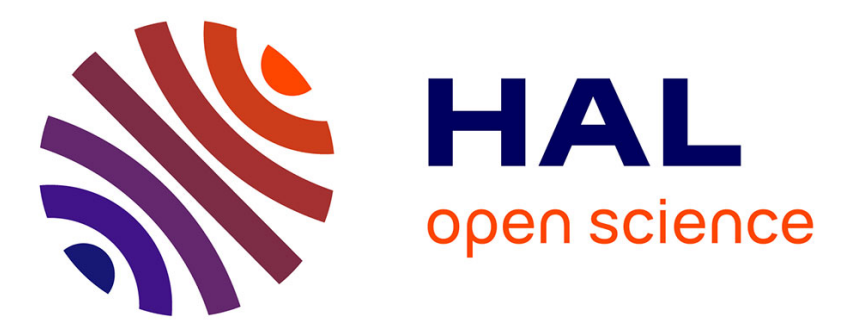

\title{
Numerical Simulation of Foam Flooding in Porous Media in the Absence and Presence of Oleic Phase
}

M. Hosseini-Nasab, F. Douarche, M. Simjoo, L. Nabzar, Bernard Bourbiaux, P.L.J. Zitha, F. Roggero

\section{- To cite this version:}

M. Hosseini-Nasab, F. Douarche, M. Simjoo, L. Nabzar, Bernard Bourbiaux, et al.. Numerical Simulation of Foam Flooding in Porous Media in the Absence and Presence of Oleic Phase. Fuel, 2018, 225, pp.655 - 662. 10.1016/j.fuel.2018.03.027 . hal-01932672

\section{HAL Id: hal-01932672 \\ https: / hal-ifp.archives-ouvertes.fr/hal-01932672}

Submitted on 23 Nov 2018

HAL is a multi-disciplinary open access archive for the deposit and dissemination of scientific research documents, whether they are published or not. The documents may come from teaching and research institutions in France or abroad, or from public or private research centers.
L'archive ouverte pluridisciplinaire HAL, est destinée au dépôt et à la diffusion de documents scientifiques de niveau recherche, publiés ou non, émanant des établissements d'enseignement et de recherche français ou étrangers, des laboratoires publics ou privés. 


\title{
Numerical Simulation of Foam Flooding in Porous Media in the
}

\section{Absence and Presence of Oleic Phase}

\author{
S.M. Hosseini-Nasab*1; F. Douarche ${ }^{2}$; M. Simjoo ${ }^{3}$; L. Nabzar ${ }^{4}$; B. Bourbiaux ${ }^{5}$; P.L.J. \\ Zitha $^{6}$, F. Roggero ${ }^{7}$
}

1, 6- Delft University of Technology, Department of Geoscience \& Engineering, Petroleum Engineering Group, Delft University of Technology, Netherlands.

2, 4, 5, 7- IFP Energies nouvelles (IFPEN), 1-4 avenue de Bois Préau, 92852, Paris, France.

3- Sahand University of Technology, Chemical Engineering Department, Iran.

\begin{abstract}
This paper presents a novel integrated approach for numerical simulation of foam coreflood experiments in the absence and presence of oil. The experiments consisted of the coinjection of gas and Alpha-Olefin Sulfonate (AOS) surfactant solution into Bentheimer sandstone samples initially saturated with the surfactant solution [see (Simjoo \& Zitha, 2013)]. The foam model implemented is based on a local equilibrium and describes dependency of foam mobility reduction factor using several independent functions, such as liquid saturation, foam velocity, oil saturation and capillary number.

First, a series of numerical simulation was conducted to investigate the effect of surfactant concentration on pressure drop across the core for the foam flooding in the absence of oil. To this end, the dry-out and gas velocity functions in the foam model were determined from the experimental data obtained at low and high-quality regimes of foam flow at a constant injection velocity. Next, pressure drop profiles of foam flooding at two different surfactant concentrations were modelled to determine the parameters of the surfactant-dependent function in the foam model. The simulation results fit the experimental data of pressure drops very well. Then, the numerical simulations investigated the oil displacement, by foam where the main goal was to determine the foam model parameters dedicated to the oil saturationdependent function. The pressure drop across the core, oil-cut, and oil recovery factor were
\end{abstract}


modelled, and an excellent match was obtained between the pressure profile and the oil recovery obtained numerically compared with those obtained from the corresponding coreflood experiments.

\section{Introduction}

Gas injection for enhanced oil recovery (EOR) suffers from poor sweep efficiency. Three reasons are associated with this deficiency of gas flooding: 1) segregation and gravity override due to the lower density of gas compared to oil and/or water, 2) viscous fingering due to high mobility ratio between injected gas and oil and/or water, 3) channelling through high-permeability streaks or layers in heterogeneous and layered reservoir (Lake et al., 2014). Although not all the gas injection methods essentially lead to the poor oil recovery efficiency. The recent method of the Gas-Assisted Gravity Drainage (GAGD) process has a good sweep efficiency and higher recovery than Continuous Gas Injection (CGI) and Water-Alternative Gas (WAG) processes, in both immiscible and miscible modes (Al-Mudhafar \& Rao, 2017).

Foam can improve the volumetric sweep efficiency by reducing gas mobility, providing a favourable mobility ratio and contacting a larger fraction of the reservoir to mitigate the effect of heterogeneity, gas segregation and viscous instability (Rossen, 1996; Farajzadeh et al., 2010; Simjoo et al., 2011). Design of the foam EOR process for field-scale application requires accurate prediction and description of foam behaviour in porous media with and without the oleic phase. Modelling of foam flow in a porous media can be categorized into two major methods: the local equilibrium with implicit texture (LE-IT) foam model, and the population balance approach. The LE-IT foam model assumes that a local steady state of foam dynamics in terms of creation and destruction of foam is reached instantaneously wherever gas and surfactant (as a foaming agent) coexist in porous media (Rossen \& Wang, 1999; Boeije \& Rossen, 2013; Ma et al., 2015;). This model implicitly takes into account the presence of foam generation and coalescence through a mobility interpolation factor which depends itself on water saturation, gas velocity and other factors (Cheng et al., 2000). Application of LE-IT foam model for the field scale requires dependency of the model parameters upon the variety of geological properties of the reservoir, in particular permeability, porosity or fracture geometry in each direction (Farajzadeh et al., 2015). The 
LE-IT empirical foam model is unable to model the correct foam density as a function of foam quality where the foam quality can vary in thick reservoirs based upon various factors such as permeability, pore size distribution etc.

The population balance approach describes the dynamics of foam generation and destruction where the foam mobility reduction is based on the bubble size and bubble density (foam texture) (Kovscek et al., 1995; 2010). Although population balance model provides a comprehensive mechanistic description of foam flow in porous media, it requires many physical parameters which are not easy to determine for the field application. On the other hand, the empirical LE-IT model is more pragmatic and simpler for the field-scale simulation as it requires fewer simulation parameters and numerical difficulties and lower computational cost compared to the population balance model (Kapetas et al., 2015; Rossen \& Boeije, 2015).

Much work in the literature has focused on the simulation of foam flooding in the absence of an oleic phase. Simjoo and Zitha (2015) studied the transient foam flow in an oil-free porous media by using the stochastic bubble population model. The premise of this model is that foam flow in porous media is a complex fluid and bubble generation is a stochastic process. They obtained a good match between the numerically calculated fluid saturation and pressure data with those obtained from the experiments at which foam was generated by coinjecting nitrogen and alpha olefin sulfonate surfactant in Bentheimer sandstone. Boeije et al. (2015) proposed a method to calculate the parameters of the water-saturation-dependent function and also shear-thinning function from the foam pressure gradient data at low and high-quality regimes at fixed total velocity. This method can provide the initial estimates for the foam model physical parameters to be used in the reservoir simulator for foam simulation at a large scale. Ma et al. (2013) estimated the parameters of the water-saturation-dependent function to describe the dry-out effect in the absence of the oil phase. In their approach, shearthinning behaviour at the low-quality regime of foam flooding was ignored.

Effect of permeability variation of porous media on the behaviour of foam flow in the absence of oil was studied experimentally and theoretically by Kapetas et al (2015). They showed permeability can have a significant impact on the critical foam saturation such that the higher permeability layer exhibits lower critical water saturation $\left(S_{w}^{*}\right)$. However, they did not come up with a robust correlation between the permeability and transition abruptness 
characteristic of the LE-IT foam model for the foam quality-scan experiments at different foam-flow regimes. Jones et al. (2016) fitted the core-flood results of foam flooding without oil, for different surfactant concentration by the LE-IT foam model. To be able to predict the effect of the concentration on the foam apparent viscosity, they extend the model such that five foam parameters vary with surfactant concentration.

Lotfollahi et al. (2015) presented a numerical model to simulate foam flooding in the presence of micro-emulsion phase. However, in this work no validation was given with respect to the experimental data. Similarly, Lashgari et al. (2015) applied the black-oil model system coupled with the micro-emulsion phase behaviour model for simulation of low-tension gas flooding. They used the interfacial tension (IFT) reduction as the main factor to control the incremental oil recovery even though this mechanism in foam flooding does not always function. Therefore, most of the works in the literature have modelled foam flow in porous media either in the absence or the presence of oleic phase. On the other hand, many experimental data of foam flooding for EOR purposes have been reported.

Thus, this study aimed to investigate the application of LE-IT foam model for numerical modelling of foam flow in the sandstone rock for both in the absence and presence of an oleic phase. The foam model of Puma-Flow reservoir simulator (IFP Energies nouvelles) was used, which is similar to the foam model in CMG-STARS simulator (Computer Modelling Group Ltd., 2007). To this end, first the parameters of the dry-out and gas velocity functions in the foam model were determined by a least-square matching of the model to the experimental data obtained at low and high-quality regimes at a constant superficial velocity. Then, numerical simulations were conducted to investigate the effect of surfactant concentration on the pressure drop across the core sample for the core-flood laboratory data of foam flooding in the absence of oil. Thereafter, the effect of oil on the modelling of foam flooding was elaborated by fitting foam parameters to experimental data of the foam flooding in the presence of oil. The structure of this paper is as follows. First, we describe the main features of the foam model used in this study. Next we present an overview of the experimental study on foam flooding in sandstone porous media with and without oleic phase. The paper proceeds with the simulation results obtained from numerical modelling of the experimental data, and finally the main conclusions are drawn. 


\section{Theoretical Description of LE-IT Foam Model}

Features of local equilibrium and implicit-texture (LE-IT) foam model, in the PumaFlow simulator (in-house reservoir simulator of IFPEN), are described as follows. Reduction of gas mobility due to presence of a foaming agent is assigned to the relative permeability function, while gas-phase viscosity is assumed unchanged no matter whether a foaming agent is present or not. The relative permeability reduction factor is interpolated between a (maximum) reference value known or measured in optimal foaming conditions and a unity value in the absence of the foaming agent. Gas relative permeability in the presence of foam, $k_{r g}^{\text {foam }}$, is rescaled to gas relative permeability in the absence of foam, $k_{r g}^{g a s}$, by multiplying $k_{r g}^{g a s}$ by a dimensionless interpolation factor, $F M$.

$$
k_{r g}^{\text {foam }}=k_{r g}^{g a s} \times F M
$$

The interpolation function $(F M)$, also known as the mobility reduction factor, is a product of various functions to capture the different physical effects on the foam stability in porous media. The $F M$ function generally includes the contributions of four variables, namely surfactant concentration, water saturation, gas phase velocity and oil saturation.

$$
F M=\frac{1}{1+\left(M_{r e f}-1\right) F_{1} F_{2} F_{3} F_{4}}
$$

The term $M_{\text {ref }}$ is the (reference) maximum foam mobility reduction factor obtained without the impact of other factors $\left(F_{1}, F_{2} \ldots\right)$. The functions $F_{1}, F_{2}, F_{3}$ and $F_{4}$ incorporate the effects of foaming agent concentration, water saturation, oil saturation and capillary number (gas phase velocity) respectively. The $F_{i}$ values are within the range $[0 ; 1]$ : the closer they are to 1 the more efficient the foam will be. Through the indices one can decide to neglect the dependency on some parameters by simply inputting $e_{i}=0$.

$$
F_{1}=\left[\frac{\operatorname{Min}\left(\bar{C}_{f, W}, \bar{C}_{f, W}^{r e f}\right)}{\bar{C}_{f, W}^{r e f}}\right]^{e_{s}}
$$




$$
\begin{aligned}
& F_{2}=0.5+\frac{\arctan \left[f_{w}\left(S_{w}-S_{w}^{*}\right)\right]}{\pi} \\
& F_{3}=\left[\frac{\max \left(0, S_{O}^{*}-S_{o}\right)}{S_{O}^{*}}\right]^{e_{o}} \\
& F_{4}=\left[\frac{N_{c}^{r e f}}{\max \left(N_{c}, N_{c}^{r e f}\right)}\right]^{e_{c}}
\end{aligned}
$$

$F_{1}$ is a power-law relationship to describe the effect of foaming agent concentration. It is controlled by parameters $\bar{C}_{f, W}^{r e f}$ and $e_{S}$, where $\bar{C}_{f, W}^{r e f}$ is the critical surfactant concentration above which gas mobility is independent of surfactant concentration $\left(C_{s}\right) . \bar{C}_{f, W}^{\text {ref }}$ depends on surfactant type and is larger than the critical micelle concentration (CMC). When surfactant concentration is larger than the CMC value, foam becomes more stable due to the increase of disjoining pressure (Kovscek \& Radke, 1994; Schramm \& Smith, 1996). Note that foam coalescence rate is lower than foam film creation rate, as long as the disjoining pressure is larger than the local capillary pressure (Buchavzov \& Stubenrauch, 2007; Ekserova \& Krugliakov, 1998; Schulze-Schlarmann et al., 2006).

$F_{2}$ is namely foam dry-out function which describes the dependence of foam strength on water saturation $S_{w} . S_{w}^{*}$ in the function $F_{2}$ is the critical water saturation at which the maximum foam strength is reached in a high-quality regime ('foam quality' referring to gas fractional flow), and below which foam weakens in a low-quality regime (Kam \& Rossen, 2003). For the water saturation lower than $S_{w}^{*}$ as foam quality increases, foam (in a highquality regime) begins to significantly dry out and coarsen by the 'limiting capillary pressure, $P_{c}^{*}$ (Khatib et al., 1988). During a foam quality-scan test with a fixed superficial velocity, the high-quality regime is the range of foam quality where the pressure gradient decreases with increasing foam quality, while in the low-quality regime the pressure gradient increases with increasing foam quality (Tanzil, Hirasaki, \& Miller, 2002). In the $F_{2}$ function, $f_{w}$ is the dryout coefficient that controls the collapse rate of the foam in the high-quality regime as a function of water saturation (Kapetas et al., 2015). This coefficient $\left(f_{w}\right)$ has a significant effect on the predictions of pressure gradient particularly near the transition between the low/high- 
quality regimes.

Larger values of $f_{w}$ yield a sharper transition between the high and low-quality regimes, which means that foam dries out faster, while small values cause a gradual transition between the foam flow regimes, which means that the foam gradually dries out. If the transition between high and low-quality regimes is abrupt, then the $S_{w}^{*}$ parameter corresponds to the water saturation at the limiting capillary pressure $P_{c}{ }^{*}$, i.e. the water saturation at which foam strength collapses (Gauglitz et al., 2002). $F_{3}$ represents the destabilization effect of oil on the foam stability. The $S_{o}^{*}$ parameter is the oil saturation threshold above which foam is destroyed and gas mobility is not reduced at all. The $e_{o}$ is the exponent of the function of $F_{3}$, which controls the rate of disappearance of the foam when oil is present. By setting a zero value for this exponent, one can neglect any detrimental effect of the presence of oil on the generated foam and thus, on the gas mobility control properties.

$F_{4}$ is the shear-thinning velocity effect that represents the influence of non-Newtonian power-law shear thinning of foam rheology on the foam strength. It has been seen that the apparent foam viscosity decreases as the velocity increases, which makes the foam look like a non-Newtonian shear thinning fluid (Hirasaki \& Lawson, 1985; Xu \& Rossen, 2003). In $F_{4}$ function, $N_{c}$ is the capillary number, and $0<N_{c}^{r e f}<1$ is a range of reference capillary number values. $N_{c}$ is a dimensionless number, which is defined by the ratio of viscous forces to capillary forces. It is defined by the following equation:

$$
N_{c}=u \times \mu_{a p p} / \varphi \sigma_{w g}=k \times \nabla p / \sigma_{w g}
$$

where $u$ is the total Darcy velocity (gas+liquid), $\mu_{a p p}$ is the apparent viscosity of the displacing fluid in the porous media, $\varphi$ is porosity of rock, $k$ is absolute permeability of rock, $\nabla p$ is the pressure gradient, and $\sigma_{w g}$ is the surface tension between gas and foaming agent solution, which is a function of the concentration of foaming agent in the aqueous phase. Other definitions of the capillary number have been used in the literature (Lake et al., 2014), but Eq. (7) is the most commonly used for foam flooding (Simjoo et al., 2012). The capillary pressure has an important impact on the foam stability, and in this study, the capillary number is used to model this effect. 
Since the maximum value of function $F_{4}$ is equal to 1 , therefore the value of $N_{c}^{\text {ref }}$ should be set equal to the lowest capillary number expected in the simulations. Below this value of capillary number (i.e. $N_{c}^{r e f}$ ), the shear-thinning behaviour is not represented. The parameter $e_{C}$ controls the significance of the shear-thinning effect; in which this parameter the larger it is, the stronger the shear-thinning behaviour becomes. A value of $e_{C}=0$ represents Newtonian behaviour. It is an advantage for foam to be a shear thinning fluid for improved sweep efficiency purposes in reservoir applications. This is because near the injection wellbore where the velocity is high, the apparent foam viscosity will be low and thus, the injectivity will be high (Ashoori et al., 2011). However, deep in the reservoir, the apparent foam viscosity will be high, and therefore foam will act as an efficient mobility control agent.

\section{Overview of the Core-flood Experiments}

\subsection{Materials and Methods}

Brine was prepared by adding sodium chloride $(\mathrm{NaCl}$, Merck) at a fixed concentration of $3 \mathrm{wt} \%$ in de-ionized water $(\mathrm{pH}=6.8 \pm 0.1)$. Surfactant solutions with different surfactant concentrations were prepared with the same salinity as the brine. Normal hexadecane $\left(n-C_{16}\right)$ with a density of $0.78 \pm 0.01 \mathrm{~g} / \mathrm{cm}^{3}$ was used as model oil. The surface and interfacial tensions were measured using a KSV Sigma tensiometer by the DuNouy ring method. Surface tension of $1.0 \mathrm{wt} \%$ AOS surfactant solution was $28.0 \pm 0.1 \mathrm{mN} / \mathrm{m}$, and IFT between the surfactant solution and model oil was found to be $1.9 \pm 0.1 \mathrm{mN} / \mathrm{m}$ (both measured at $20^{\circ} \mathrm{C}$ ). The critical micelle concentration of AOS solution in the presence of brine was $4.0 \times 10^{-3} \mathrm{wt} \%$. The properties of the chemicals used in this work are summarized in Table 1, and the physical properties of the core samples are presented in Table 2. Details of the experiment conditions and results can be found elsewhere (Simjoo and Zitha, 2013). 
Table 1: Properties of the materials used to conduct the experiments at the ambient Temperature $21^{\circ} \mathrm{C}$ and atmospheric pressure

\begin{tabular}{cccccc}
\hline Materials & Formulation & $\begin{array}{c}\text { Molecular } \\
\text { weight } \\
\text { (g/mole) }\end{array}$ & $\begin{array}{c}\text { Viscosity } \\
\text { (cP) }\end{array}$ & $\begin{array}{c}\text { Active } \\
\text { content } \\
\text { (wt\%) }\end{array}$ & Supplier \\
\hline Salt & $\mathrm{NaCl}$ & 58.50 & solid & 99.98 & Merck \\
Oil & $\mathrm{n}-\mathrm{C} 16$ & 226.00 & $3.3 \pm 0.01$ & 99.99 & Sigma \\
Surfactant & $\mathrm{AOS}$ & 315.00 & $1.08 \pm 0.01$ & 40.00 & Stepan \\
Gas & $\mathrm{N}_{2}$ & 28.01 & 0.017 & $99.98 \%$ & $3 \mathrm{M}$ \\
Rock & mainly $\mathrm{SiO}_{2}$ & -- & -- & $93.00 \%$ & $\begin{array}{c}\text { Bentheim } \\
\text { mine }\end{array}$ \\
\hline
\end{tabular}

Table 2: Physical properties of the core samples used in the core-flooding experiment

\begin{tabular}{ll}
\hline Core sample & Bentheimer \\
\hline Length $(\mathrm{cm})$ & $17.0 \pm 0.1$ \\
Diameter $(\mathrm{cm})$ & $3.8 \pm 0.1$ \\
Porosity $(\%)$ & $21.0 \pm 0.1$ \\
Pore volume $\left(\mathrm{cm}^{3}\right)$ & $42.5 \pm 0.5$ \\
Core density $\left(\mathrm{g} / \mathrm{cm}^{3}\right)$ & $2.65 \pm 0.02$ \\
Brine permeability (Darcy) & $2.5 \pm 0.1$ \\
\hline
\end{tabular}

\subsection{Core-flooding Set-up and Procedure}

The set-up used to perform the core-floods is shown schematically in Figure 1. The sequences and conditions used to conduct the core-flooding experiments are summarized in Table 3. 


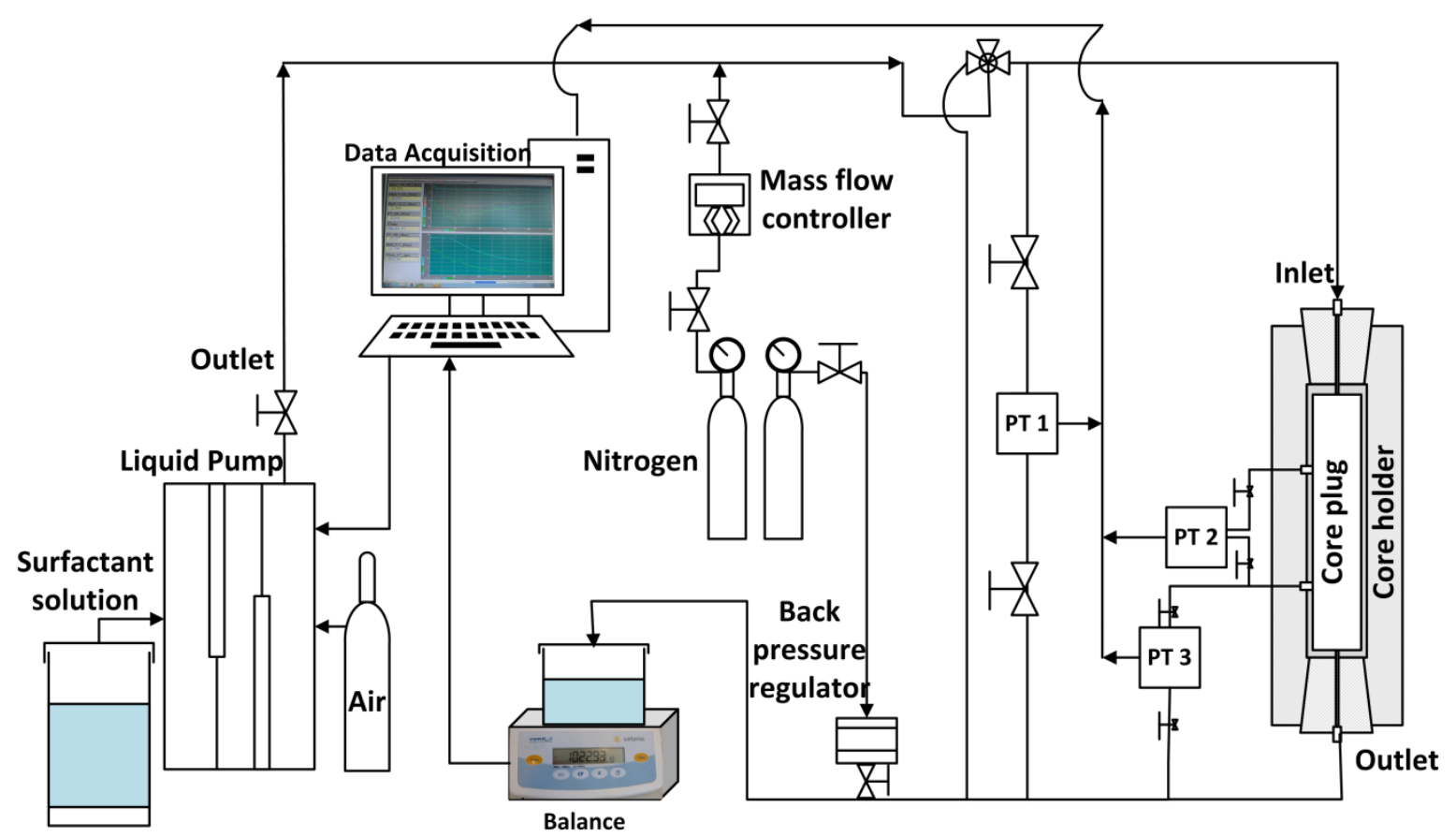

Figure 1: Schematic of the experimental set-up used to perform the core-flooding experiments. The core-holder was held vertically on the bench of the CT scanner.

First, air from the core sample was removed by flushing it with $\mathrm{CO}_{2}$ at 5 bar injection pressure. Then the dry core sample was saturated by injecting approximately 10 pore volumes (PV) of brine while increasing back-pressure up to 30 bar. Back pressure was increased to ensure that any $\mathrm{CO}_{2}$ present in the core was dissolved into the water phase $(100 \%$ core saturation with brine). For each individual experiment after core was fully saturated with brine, absolute brine permeability was measured by the standard method (Christiansen \& Howarth, 1995). For the experiments in absence of oil, core was pre-flushed with a surfactant prior to foam flooding. Surfactant pre-flush was done to satisfy the adsorption capacity of the rock surface and thus to shorten the delay in foam generation. A different injection sequence was undertaken for the experiments mimicking foam EOR: after full core saturation with brine, first oil was injected into the core till connate water saturation was reached (primary drainage). Then core was water-flooded till residual oil was reached (imbibition). Next similarly to the experiments without oil, core was pre-flushed with a surfactant solution and then subjected to foam flooding. 
Table 3: Overview of the experimental procedure used for the foam flooding experiments with and without oil

\begin{tabular}{lccc}
\hline \multicolumn{1}{c}{ Injection step sequence } & $\begin{array}{c}\text { Flowrate } \\
\left(\mathrm{cm}^{3} / \mathrm{min}\right)\end{array}$ & $\begin{array}{c}\text { Back pressure } \\
(\text { bar })\end{array}$ & $\begin{array}{c}\text { Injection } \\
\text { direction }\end{array}$ \\
\hline $\begin{array}{l}\text { Foam flooding without oil } \\
\mathrm{CO}_{2} \text { flushing to remove air }\end{array}$ & $>20$ & 5 & Downward \\
Core saturation with brine & $1.0-6.0$ & 25 & Upward \\
Surfactant preflush & 1 & 20 & Upward \\
Foam flooding (co-injection) & 1.1 & 20 & Upward \\
\hline Foam flooding with residual oil & $>20$ & 5 & Downwar \\
CO 2 flushing to remove air & $1.0-6.0$ & 25 & Upward \\
Core saturation with brine & 0.5 & 5 & Downwar \\
Oil injection (drainage) & 0.5 & 5 & Upward \\
Water flooding (imbibition) & 1 & 20 & Upward \\
Surfactant pre-flush & 1.1 & 20 & Downwar \\
Foam flooding (co-injection) & & & \\
\hline
\end{tabular}

Nitrogen gas $\left(\mathrm{N}_{2}\right)$ and surfactant solution were co-injected at a fixed superficial velocity of $4.58 \mathrm{ft} /$ day and foam quality $91 \%$, to generate foam in-situ at a back-pressure of 20 bar at ambient temperature $\left(21 \pm 1^{\circ} \mathrm{C}\right)$. Foam quality,$f_{g}$, is given by $f_{g}=q_{g} /\left(q_{g}+q_{l}\right) \times 100$, where $q_{l}$ is flow rate of the liquid phase (surfactant solution), and $q_{g}$ is flow rates of the gas phase (nitrogen).

Gas superficial velocity was determined from its nominal value by using two corrections: (1) with respect to the calibration factor for the mass flow controller (MFC) towards an adjustment of the pressure before the MFC and injection pressure after the MFC (2) with respect to the adjustment of the effect of gas compressibility of $\mathrm{N}_{2}$ due to 30 bar backpressure. For the foam-quality scan experiment with the low and high-quality regimes, the foam quality was controlled by varying the relative rates of injection of $\mathrm{N}_{2}$ gas and AOS solution at a constant superficial velocity.

\section{Results and Discussion}

\subsection{Numerical Modelling of Foam Flooding in Absence of Oil}

The objective of this section is to model the dynamic of foam generation and propagation in 
porous media in the absence of oil at the transient and steady-state flow conditions. We then model the effect of surfactant concentration on the pressure-gradient build-up during the foam flow. We illustrated the dynamics of foam generation and propagation in the porous media by the mobility reduction of full-strength foam, surfactant concentration effect, the limiting water saturation at which foam collapses, and the parameters governing foam destruction at limiting capillary pressure. To this end, we demonstrated the determination of dedicated parameters to the aforementioned characteristics of foam flow for the LE-IT foam model. First, parameters of the water saturation dependent function $\left(F_{1}\right)$, and also the parameters of capillary number dependent function $\left(F_{4}\right)$ were obtained by modelling the pressure gradient core-flood data of one scan of $\mathrm{N}_{2}$-foam quality at a fixed superficial velocity. In the absence of oil at a fixed surfactant concentration and total velocity, the LE-IT foam model related the foam mobility reduction factor, $F M$ presented in Eq. (2), only to two functions of water saturation and capillary number as follows:

$$
F M=\frac{1}{1+\left(M_{r e f}-1\right) \times\left(0.5+\frac{\tan ^{-1}\left[f_{w}\left(S_{w}-S_{w}^{*}\right)\right.}{\pi}\right) \times\left(\frac{N_{c}^{r e f}}{\max \left(N_{c}, N_{c}^{r e f}\right)}\right)^{e_{c}}}
$$

In the absence of foam, Corey-type relative permeability for water and gas phases were used as follows:

$$
\begin{aligned}
& k_{r w}\left(S_{w}\right)=k_{r w}^{0}\left(\frac{S_{w}-S_{w c}}{1-S_{w c}-S_{g r}}\right)^{n_{w}} \\
& k_{r g}\left(S_{w}\right)=k_{r g}^{0}\left(1-\frac{S_{w}-S_{w c}}{1-S_{w c}-S_{g r}}\right)^{n_{g}}
\end{aligned}
$$

where $k_{r w}^{0}$ and $k_{r g}^{0}$ are the endpoint relative permeabilities for water and gas, respectively, $n_{w}$ and $n_{g}$ are the corresponding exponents, $S_{w c}$ is connate water saturation and $S_{g r}$ is residual gas saturation. The LE-IT foam model captures the value of each function to a maximum of unity. Thus, the value of the reference capillary number $\left(N_{c}^{r e f}\right)$ was set equal to the lowest capillary number expected in the simulations, where below this value $\left(N_{c}^{r e f}\right)$, 
shear-thinning behaviour in the low-quality regime does not exist (Boeije \& Rossen, 2015). This implies that $N_{c}^{r e f}$ was not considered a foam matching parameter while other four independent parameters $M_{r e f}, S_{w}^{*}, f_{w}$, and $e_{c}$ were considered fitting parameter in the low and high-quality regimes of foam flooding in porous media. To determine these parameters, a non-linear least-square optimization was used in which all the four foam parameters were computed simultaneously. For this, an initial guess and an allowed range were considered for each parameter. Table 4 presents the input parameters of rock-fluid properties, relative permeability parameters of gas and liquid phases (Eqs. (9) and (10)), and conditions of the foam flooding experiment that were implemented in the numerical simulation.

Table 4: Input values of rock, fluids and relative permeability parameters in the simulation

\begin{tabular}{ll}
\hline Input parameters & Values \\
\hline Number of grid blocks & $1 \times 1 \times 100$ \\
Grid block size $(\mathrm{m} \times \mathrm{m} \times \mathrm{m})$ & $0.0367 \times 0.0367 \times 0.0017$ \\
Brine permeability & $2.30(\mathrm{Darcy})$ \\
Porosity & 0.25 \\
Temperature & $21^{\circ} \mathrm{C}$ \\
Brine viscosity & $1.0(\mathrm{cP})$ \\
Brine density & $1.0\left(\mathrm{gr} / \mathrm{cm}^{3}\right)$ \\
Water compressibility factor & $5.0 \mathrm{E}^{-5}$ \\
Gas viscosity & $0.01744-0.01832(\mathrm{cP})$ \\
Surfactant concentration & $1.0,0.5, \mathrm{wt} \%$ \\
Salinity (water flooding) & $3.0 \mathrm{wt} \%(\mathrm{NaCl})$ \\
Injection flowrate & $1.1\left(\mathrm{~cm}^{3} / \mathrm{min}\right)$ \\
Producer bottom hole pressure & $20 \mathrm{bar}$ \\
Foam injection time & $20(\mathrm{PV})$ \\
Connate (irreducible) water saturation & 0.15 \\
Residual gas saturation & 0 \\
Water relative permeability endpoint & 0.25 \\
Gas relative permeability endpoint & 0.76 \\
Exponent of water relative permeability & 2 \\
Exponent of gas relative permeability & 1.3 \\
\hline
\end{tabular}

In order to compute the capillary number, a function describing the dependence of the gaswater surface tension versus surfactant concentration was implemented. Then, the stabilizing effect of the surfactant concentration on the generated foam was modelled using the dependence of capillary number due to the variation of gas-water surface tension. The values of the foam matching parameters obtained by least-square optimization method are summarized in Table 5. Numerical simulation of the foam flooding pressure drop of foam- 
quality scan experiment without oil is shown in Figure 2. It demonstrates a very good fit of the simulations to the experimental data was obtained.

Table 5: Foam model parameters for the numerical modelling of foam flooding pressure drop at low/high-quality regimes in the absence of an oil phase

\begin{tabular}{ll}
\hline Parameters & Values \\
\hline Reference mobility reduction factor, $M_{\text {Ref }}$ & 48500 \\
Reference surfactant concentration, $\bar{C}_{f, W}^{r e f}$ & $6(\mathrm{~g} / \mathrm{L})$ \\
Exponent of surfactant function, $e_{s}$ & 1.5 \\
Reference capillary number, $N_{c}^{r e f}$ & $9.76 E^{-6}$ \\
Critical water saturation, $S_{w}{ }^{-6}$ & 0.16 \\
Constant of driving foam evolution, $f_{w}$ & 1000 \\
\hline
\end{tabular}

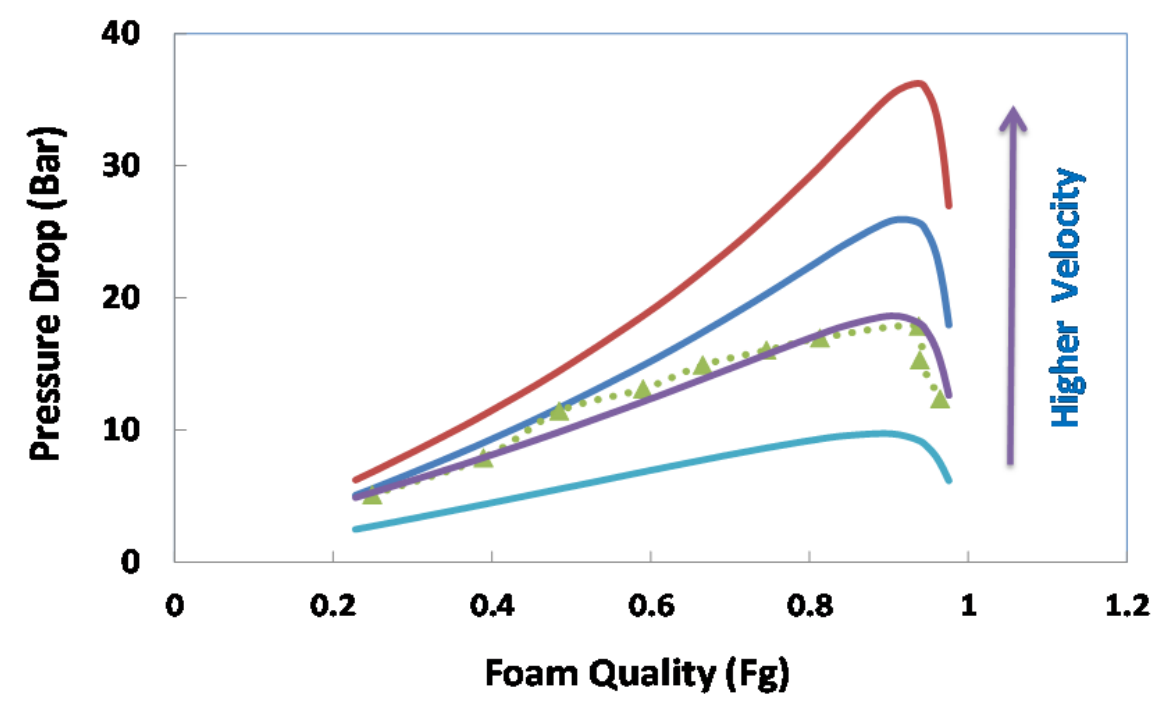

Figure 2: History match of the pressure drop of foam-quality scan experiment without oil at fixed total superficial velocity $\left(U_{g}+U_{w}\right.$ ) (at $4.58 \mathrm{ft} /$ day and $91 \%$ foam quality) in Bentheimer core by the LE-IT foam model and the simulation parameters presented in Table 5. Numerically simulated behaviour of foam-quality scans at a fixed superficial velocity that are higher and lower superficial velocities than the experimental condition are also shown in this figure.

Calculated pressure drops from numerical simulation for higher and lower total superficial velocity than the experimental results are also presented in Figure 2. It illustrates that the rheological characteristics and foam-flow regimes in a foam quality-scan experiment with the different velocities can also be captured by the numerical results, where the pressure gradient first increased with increasing foam quality, and then the pressure gradient decreased due to the foam dry-out. The constant of driving foam evolution $\left(f_{w}\right)$ of foam dry-out function was not considered a large value for the set of data examined in this work, because the transition 
from low-quality to high-quality regime is not abrupt and the generated foam does not collapse at a constant water saturation as shown in Figure 2 (Kapetas et al., 2015; Rossen \& Boeije, 2015).

In order to test the capability of the LE-IT foam model to describe the effect of the surfactant concentration, numerical simulation of the pressure drop for foam flooding at two different concentrations was performed. Five foam model parameters of dry-out function $\left(F_{2}\right)$ and gas velocity effect $\left(F_{4}\right)$ determined from the previous simulation of foam flood at low/high-quality regimes were used. Then, the reference surfactant concentration and the exponent of the surfactant-effect function $\left(F_{l}\right)$ of the foam model, by fitting to the experimental data of pressure drop of foam flow at two different concentrations were estimated as earlier presented in Table 5. The foam existence was considered to be a function of the surfactant (foaming agent) concentration and water saturation. Figure 3 shows numerically calculated pressure drop versus experimental data at transient and steady-state regimes for $0.5 \mathrm{wt} \%$ and $1.0 \mathrm{wt} \%$ surfactant concentrations.

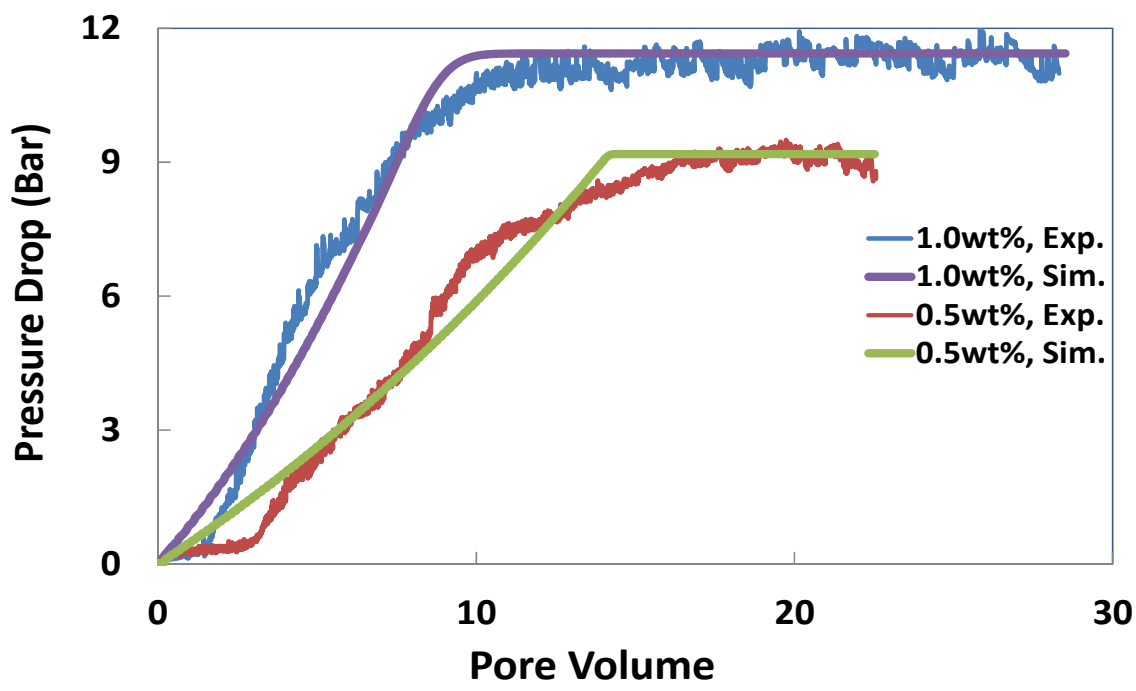

Figure 3: Comparison of numerically calculated and measurement pressure drops of foam flooding in the absence of oil at two different surfactant concentrations. Total superficial velocity and foam quality at injection side of the core was fixed at $4.58 \mathrm{ft} /$ day and $91 \%$, respectively.

The results describe mobilities at fixed total superficial velocity for the tow different surfactant concentrations. The LE-IT foam model successfully captured the experimental fronts and provided a good match for the foam propagation rate at the transient and steady- 
state conditions. However, initiation of foam generation and propagation by the model are slightly higher than those obtained experimentally. Simulated pressure drop profile in the case of the lower surfactant concentration $(0.5 \mathrm{wt} \%)$ at the earlier time of the transient state mimics less features of the experimental results due to the delayed foam generation.

\subsection{Simulation of Foam Flooding in Presence of Oil}

The objective of this section is the numerical simulation of the core-flood experimental data of immiscible foam flooding during the displacement of the water-flooded remaining oil. Modelling foam propagation through the porous media in the presence of oil is essential to predict the performance of the immiscible foam EOR process. In this section, we assumed that the destabilizing effect of oil on the foam is a function of oil and water saturations. The total foam coalescence rate is the summation of the coalescence rate due to the water dry-out near the limiting water saturation (Eq. (4)), and also due to the presence of oil (Eq. (5)).

Table 6 summarizes the input parameters, and other conditions of the foam flooding experiment that were implemented in the numerical simulation. The reservoir model used for the vertical one-dimensional simulation of the core-flow system had dimensions $1 \times 1 \times 100$ grid blocks. No-flow boundries were imposed on the lateral sides of the core sample along with in- and out-flow conditions. Reservoir model was isothermal with the temperature constant at $22^{\circ} \mathrm{C}$, the initial pressure of 20 bar, the porosity of $23 \%$ and the permeability was 2.1 Darcy.

Table 6: Input values of the parameters of the reservoir model in the simulation

\begin{tabular}{ll}
\hline Input parameters & Values \\
\hline Number of grid blocks & $1 \times 1 \times 100$ \\
Gris block size $(\mathrm{m} \times \mathrm{m} \times \mathrm{m})$ & $0.0367 \times 0.0367 \times 0.0017$ \\
Brine permeability & $2.1(\mathrm{Darcy})$ \\
Porosity & 0.21 \\
Oil viscosity & $3.2 \pm 0.2(\mathrm{cP})$ \\
Oil density & $0.79\left(\mathrm{~g} / \mathrm{cm}^{3}\right)$ \\
Connate (irreducible) water saturation & 0.15 \\
Residual oil saturation after water flooding & 0.43 \\
Residual oil saturation after foam flooding & 0.19 \\
Salinity (water flooding) & $3 \mathrm{wt} \%(\mathrm{NaCl})$ \\
Producer bottom hole pressure & $20 \mathrm{bar}$ \\
Injection flowrate & $1.1\left(\mathrm{~cm}^{3} / \mathrm{min}\right)$ \\
Surfactant concentration & $1.0 \mathrm{wt} \%$ \\
\hline
\end{tabular}




\begin{tabular}{ll}
\hline Foam injection time & $18(\mathrm{PV})$ \\
Residual gas saturation & 0 \\
Endpoint of water for water/oil relative permeability & 0.26 \\
Endpoint of oil for water/oil relative permeability & 0.75 \\
Exponent of water for water/oil relative permeability & 2.50 \\
Exponent of oil for water/oil relative permeability & 1.80 \\
Endpoint of gas for gas/oil relative permeability & 0.55 \\
Endpoint of oil for gas/oil relative permeability & 0.51 \\
Exponent of gas for gas/oil relative permeability & 1.50 \\
Exponent of oil for gas/oil relative permeability & 3.10 \\
\hline
\end{tabular}

Immediately before foam flooding, the reservoir model was at the water-flooded residual oil saturation $\left(S_{o r}=0.44\right)$, with no gas initially present in the core. The injector and producer were placed at opposite ends of the reservoir model, and injection rate was performed at a rate of $4.2 \mathrm{ft} /$ day. The maximum bottom-hole pressure (BHP) in the injector and producer was set 50 bar and 30 bar, respectively. $\mathrm{N}_{2}$ gas and surfactant solution were co-injected at a fixed gas fraction into the flow system of the reservoir model with a uniform water fraction of 0.09 (foam quality of 91\%). The binary relative permeability curves between gas/oil and water/oil were used for the 1D displacement simulation. A Corey-type equation was used to describe the relative permeabilities. The binary relative permeability curves were combined into a ternary relative permeability function using a three-phase model of Stone I (Stone, 1973). The three-phase oil relative permeability was computed with the Stone I model and applied to calculate the residual oil saturation parameter. The effects of oil saturation on foam was incorporated by implementing the parameters of $F_{3}$ function (Eq. (5)) as presented in Table 7. It is essential to note that the $F_{i}$ in the $F M$ function were multiplied together. Then, if several parameters are not favorable, then the foam stability will be strongly impacted.

Table 7: Foam model parameters for numerical simulation of the pressure drop and oil recovery by foam flooding in the presence of oil

\begin{tabular}{ll}
\hline Parameters & Values \\
\hline Reference mobility reduction factor, $M_{\text {Ref }}$ & 45000 \\
Critical oil saturation, $S_{O}^{*}$ & 0.5 \\
Exponent of oil effect function, $e_{o}$ & 0.2 \\
Reference surfactant concentration, $\bar{C}_{f, W}^{r e f}$ & $0.35 \mathrm{wt} \%$ \\
Exponent of surfactant-dependent function, $e_{s}$ & 0.5 \\
Reference capillary number, $N_{c}^{r e f}$ & $9.78 \mathrm{E}^{-6}$ \\
\hline
\end{tabular}




\begin{tabular}{ll}
\hline Exponent of capillary number function, $e_{c}$ & 0.2 \\
Critical water saturation, $S_{w}{ }^{*}$ & 0.15 \\
Constant driving of foam evolution, $\left(f_{w}\right)$ & 100 \\
\hline
\end{tabular}

Figure 4 compares the pressure drop and oil recovery factor (with respect to OIIP) obtained from numerical simulation and the experiments. The results show a good qualitative agreement between the simulated and measured pressure drop data. The simulated pressure drop increased until reaching a minimum-pressure gradient to generate strong foam in the transient state, and after pressure drop raised, then levelled off to a plateau value during the steady-state condition of foam flow regime. One can see small fluctuations in the pressure drop after the chemical breakthrough for the experimental data and modelling results. Also Figure 4 shows a good match of the simulated and measured oil recovery by immiscible foam flooding. However, there is a small discrepancy between the numerically calculated and measured oil recovery data between 1.5 and $3.0 \mathrm{PV}$, most likely due to the lower oil relative permeability during the three phase flow of oil displacement experiment by foam flooding (Heins et al., 2014; Simjoo \& Zitha, 2015). Thus, this plot (Figure 4) demonstrates an acceptable fit to the series of pressure drops and oil recover factor at both the transient and steady-state conditions of foam generation and propagation through the porous media.

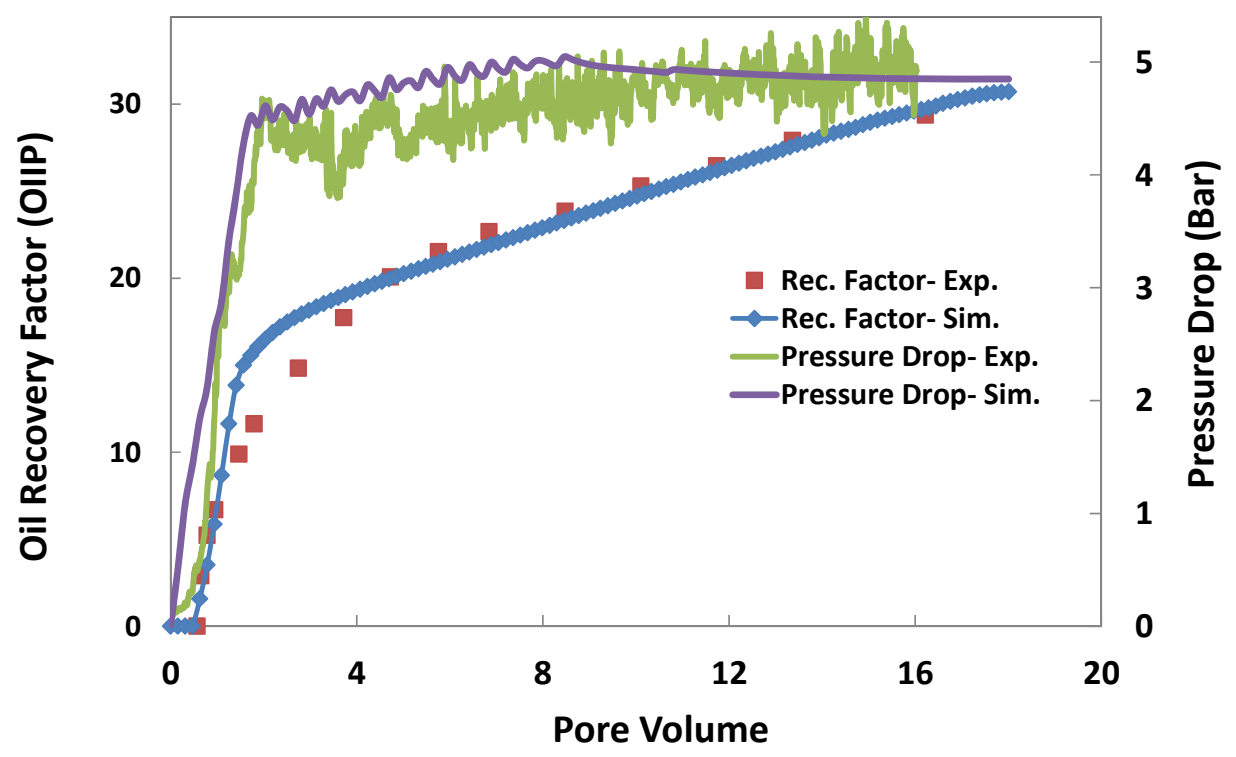

Figure 4: Comparison of numerically calculated and measured pressure drops and oil recovery factor (OIIP) during oil displacement by foam flooding. 


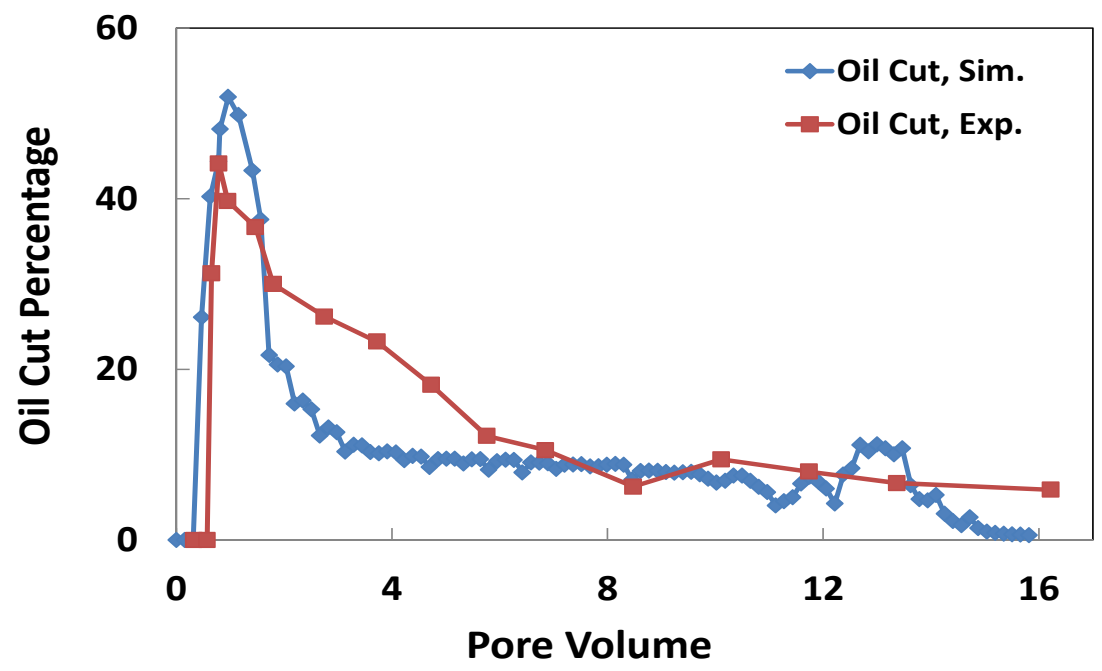

Figure 5: Comparison of numerically calculated and measured oil-cut by foam flooding.

Figure 5 compares the oil-cut (normalized oil production rate) profile obtained from numerical simulation with those obtained from the experiments. The numerically predicted oil-cut profile is in a good agreement with the one obtained from the experiment. In the first 1.2 pore volumes, the oil-cut increases until it reaches a peak value of $54 \%$ and then decreases towards $5.8 \%$ over more than 15 pore volumes. Visual inspection of the effluents showed that in the first 1.8 PV clean oil was produced while after oil was produced as an oilin-water emulsion (Simjoo \& Zitha, 2013). This means that foam flooding first induces the formation of an oil bank and then, after the breakthrough of the trailing edge of the oil bank, the diffuse oil is obtained as a dispersed phase. The above oil production features due to foam flooding, i.e. oil bank followed by a long tailing oil recovery, were captured remarkably well by the numerical simulations. The tailing oil production occurred during the highest capillary number (or pressure build-up, see Figure 5), and produced oil was attributed to the emulsified oil. The desaturation of the oleic phase from the core can also be elaborated from the series of CT scan images obtained during foam flooding as presented in Figure 6. The red color corresponds to the liquid phase consisting of residual oil plus surfactant solution. As gas and surfactant solution were co-injected from the top of the core, the intensity of the orange colour diminishes from the left to right progressively in favour of more blue, corresponding threephase flow. This gives a qualitative impression of the change in fluid saturations including oil saturation in the core. 


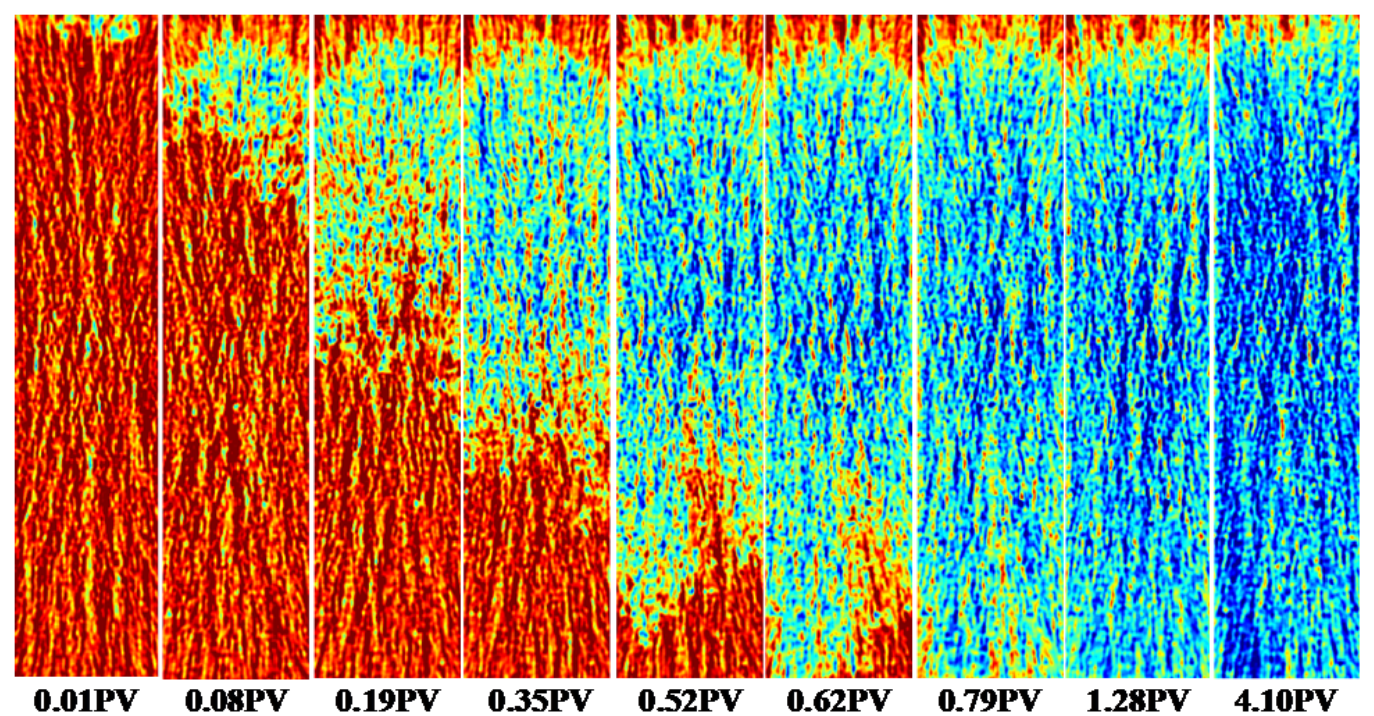

Figure 6: CT images obtained during foam flooding in a core containing water-flooded residual oil (Simjoo \& Zitha, 2013). The red colour stands for the water-flooded core including residual oil saturation, and the blue colour indicates the presence of the foam phase. Foam was injected from top to bottom to ensure gravity stable conditions. Foam breakthrough occurred at $0.63 \pm 0.02 \mathrm{PV}$.

\section{Conclusion}

The study presented in this work demonstrated an integrated approach for the numerical simulation of foam transport in porous media with and without the oleic phase. First, the LEIT foam model was matched to the foam core-flood experiments in the absence of the oleic phase by taking into account the foam dry-out phenomena, rheological characteristics along with shear thinning properties and foam-quality regimes. The parameters of the watersaturation and the shear-rate dependent functions $\left(F_{2}\right.$ and $\left.F_{4}\right)$ were determined by historymatching the foam quality-scan data at the steady-state condition, in the low/high quality regimes. The corresponding parameters of $F_{2}$ and $F_{4}$ functions were then used to model the effect of surfactant concentration on the pressure build-up induced by foam. The parameters of the surfactant-concentration dependent function $\left(F_{l}\right)$ were obtained by matching the numerical and experimental pressure drop data for the transient and steady-state conditions.

The numerical simulation of foam flooding in the presence of water-flooding residual oil was performed by estimating the oil-saturation dependent function of the foam mobility interpolation factor. The numerically calculated pressure drop fitted well the experimental lab data of the transient and steady-state foam generation and propagation in the presence of oil. Two distinct regimes of incremental oil production were captured by the numerical 
simulation, first by the formation of an oil bank and then followed by a long tail production. The results of this study showed that the developed numerical model reproduced the main feature of the transient and steady-state foam flow regimes in presence of oleic phase. This was supported by a good match between pressure and oil recovery profiles obtained numerically with those obtained from the foam flooding EOR experiment in the Bentheimer sandstone core samples. The small discrepancy between the numerically calculated and measured oil recovery data, most likely was due to the lower oil relative permeability during the three phase flow of oil displacement experiment by foam flooding.

\section{Nomenclature}

SI units are assumed for all parameters used in calculations.

$\begin{array}{cl}\bar{C}_{f, W}^{r e f} & \text { reference surfactant concentration } \\ e_{c} & \text { exponent of capillary number function, } \\ e_{o} & \text { exponent of oil effect function } \\ e_{s} & \text { exponent of surfactant-dependent function } \\ f_{w} & \text { constant of driving foam evolution } \\ f_{g} & \text { foam quality } \\ F_{l} & \text { surfactant dependent function } \\ F_{2} & \text { water saturation dependent function } \\ F_{3} & \text { capillary number dependent fuction } \\ F_{4} & \text { oil saturation dependent function } \\ k & \text { absolute permeability of rock for water phase } \\ k_{r g}^{g a s} & \text { gas relative permeability in absence of foam } \\ k_{r g}^{f o a m} & \text { gas relative permeability in presence of foam } \\ k_{r w}^{0} & \text { endpoint of water for water/gas relative permeability } \\ k_{r g}^{0} & \text { endpoint of gas for water/gas relative permeability } \\ M_{r e f} & \text { reference foam mobility reduction factor } \\ n_{w} & \text { exponent of water for water/gas relative permeability } \\ n_{g} & \text { exponent of gas for water/gas relative permeability } \\ N_{c}^{r e f} & \text { reference capillary number } \\ P_{c}^{*} & \text { limiting capillary pressure } \\ q_{g} & \text { flow rate of the gas phase } \\ q_{l} & \text { flow rate of the water phase } \\ S_{w c} & \text { connate water saturation } \\ S_{g r}^{*} & \text { residual gas saturation } \\ S_{w} & \text { critical water saturation } \\ \end{array}$




$\begin{array}{cl}S_{O}^{*} & \text { critical oil saturation } \\ u & \text { total superficial velocity } \\ \nabla p & \text { pressure gradient } \\ \varphi & \text { porosity of rock sample } \\ \mu_{a p p} & \text { Apparent viscosity of displacing fluid (foam) } \\ \sigma_{w g} & \text { surface tension between gas and surfactant solution }\end{array}$

\section{Acknowledgement}

Shell Global Solutions B.V. is gratefully acknowledged for partially funding of the laboratory experiments presented in this paper through its Gamechanger programme. Our especial thanks to Descartes French Excellence Scholarships funded by TOTAL company, for the financial support to conduct this research at the IFP Energy Nouvel (IFPEN) in France. We would like to thank M. Friebl, E, Meivogel and H. Asten for technical supports at Dietz Laboratory of the Geoscience and Engineering department of TU Delft.

\section{References.}

Al-Mudhafar, W. J., \& Rao, D. (2017). Lessons Learned from the Field-Scale Simulation of the Gas-Assisted Gravity Drainage GAGD Process in Heterogeneous Sandstone Oil Reservoirs. In SPE Western Regional Meeting. Society of Petroleum Engineers. https://doi.org/10.2118/185732-MS

Ashoori, E., Marchesin, D., \& Rossen, W. R. (2011). Dynamic foam behavior in the entrance region of a porous medium. Colloids and Surfaces A: Physicochemical and Engineering Aspects, 377(1), 217-227. https://doi.org/10.1016/j.colsurfa.2010.12.043

Boeije, C. S., \& Rossen, W. R. (2013). Fitting Foam Simulation Model Parameters to Data, (April 2013), 16-18.

Boeije, C. S., \& Rossen, W. R. (2015). Fitting Foam-Simulation-Model Parameters to Data : I . Coinjection of Gas and Liquid, (February).

Buchavzov, N., \& Stubenrauch, C. (2007). A disjoining pressure study of foam films stabilized by mixtures of nonionic and ionic surfactants. Langmuir, 23(10), 5315-5323. https://doi.org/10.1021/la063642u

Cheng, L., Reme, A. B., Shan, D., Coombe, D. A., \& Rossen, W. R. (2000). Simulating Foam Processes at High and Low Foam Qualities. In SPE/DOE Improved Oil Recovery Symposium. Society of Petroleum Engineers. https://doi.org/10.2118/59287-MS

Christiansen, R. L., \& Howarth, S. M. (1995). Literature Review and Recommendation of Methods for Measuring Relative Permeability of Anhydrite from the Salado Formation at the Waste Isolation Pilot Plant.

Ekserova, D. R. (Dochi R., \& Krugliakov, P. M. (Petr M. (1998). Foam and foam films : theory, experiment, application. Elsevier.

Farajzadeh, R., Andrianov, A., \& Zitha, P. L. J. (2010). Investigation of immiscible and miscible foam for enhancing oil recovery. Industrial and Engineering Chemistry 
Research, 49(4), 1910-1919. https://doi.org/10.1021/ie901109d

Farajzadeh, R., Lotfollahi, M., Eftekhari, a. a., Rossen, W. R., \& Hirasaki, G. J. H. (2015). Effect of Permeability on Implicit-Texture Foam Model Parameters and the Limiting Capillary Pressure. Energy \& Fuels, 29(5), 3011-3018. https://doi.org/10.1021/acs.energyfuels.5b00248

Gauglitz, P. A., Friedmann, F., Kam, S. I., \& Rossen, W.(2002). Foam generation in homogeneous porous media. Chemical Engineering Science, 57(19), 4037-4052. https://doi.org/10.1016/S0009-2509(02)00340-8

Heins, R., Simjoo, M., Zitha, P. L. J., \& Rossen, W. R. (2014). Oil Relative Permeability During Enhanced Oil Recovery by Foam Flooding Coreflood Experiments. Spe, 1(1), 17.

Hirasaki, G. J., \& Lawson, J. B. (1985). Mechanisms of Foam Flow in Porous Media: Apparent Viscosity in Smooth Capillaries. Society of Petroleum Engineers Journal, 25(2), 176-190. https://doi.org/10.2118/12129-PA

Jones, S. A., Laskaris, G., Vincent-Bonnieu, S., Farajzadeh, R., \& Rossen, W. R. (2016). Effect of surfactant concentration on foam: From coreflood experiments to implicittexture foam-model parameters. Journal of Industrial and Engineering Chemistry. https://doi.org/10.1016/j.jiec.2016.03.041

Kam, S. I., \& Rossen, W. R. (2003). A Model for Foam Generation in Homogeneous Media. SPE Journal, 8(4), 417-425. https://doi.org/10.2118/87334-PA

Kapetas, L., Vincent-Bonnieu, S., Farajzadeh, R., Eftekhari, a. a., Mohd-Shafian, S. R., Kamarul Bahrim, R. Z., \& Rossen, W. R. (2015). Effect of Permeability on Foam-model parameters - An Integrated Approach from Coreflood Experiments through to Foam Diversion Calculations. IOR 2015 - 18th European Symposium on Improved Oil Recovery, (April 2015), 14-16. https://doi.org/10.3997/2214-4609.201412124

Khatib, Z. I., Hirasaki, G. J., \& Falls, A. H. (1988). Effects of Capillary Pressure on Coalescence and Phase Mobilities in Foams Flowing Through Porous Media. SPE Reservoir Engineering, 3(3), 919-926. https://doi.org/10.2118/15442-PA

Kovscek, A. R., Chen, Q., \& Gerritsen, M. (2010). Modeling Foam Displacement With the Local-Equilibrium Approximation: Theory and Experimental Verification. SPE Journal, 15(1), 171-183. https://doi.org/10.2118/116735-PA

Kovscek, A. R., Patzek, T. W., \& Radke, C. J. (1995). A mechanistic population balance model for transient and steady-state foam flow in Boise sandstone. Chemical Engineering Science, 50(23), 3783-3799. https://doi.org/10.1016/0009-2509(95)00199-F

Kovscek, A. R., \& Radke, C. J. (1994). Fundamentals of Foam Transport in Porous Media (pp. 115-163). https://doi.org/10.1021/ba-1994-0242.ch003

Lake, L. W., Russell, J., \& Rossen, B. (2014). Fundamentals of Enhanced Oil Recovery. Retrieved February 1, 2015, from http://txessarchive.org/documents/J_EOR_ppt.pdf

Lashgari, H. R., Sepehrnoori, K., \& Delshad, M. (2015). Modeling of Low-Tension Surfactant-Gas Flooding Process in a Four-Phase Flow Simulator, (1973).

Lotfollahi, M., Varavei, A., Delshad, M., Farajzadeh, R., \& Pope, G. a. (2015). A Four-Phase Flow Model to Simulate Chemical EOR with Gas. SPE Reservoir Simulation Symposium. https://doi.org/10.2118/173322-MS

Ma, K., Lopez-salinas, J. L., Puerto, M. C., Miller, C. A., Biswal, S. L., \& Hirasaki, G. J. (2013). Estimation of Parameters for the Simulation of Foam Flow through Porous Media . Part 1 : The Dry-Out E ff ect.

Ma, K., Ren, G., Mateen, K., Morel, D., \& Cordelier, P. (2015). Modeling Techniques for Foam Flow in Porous Media. SPE Journal, (June).

Rossen, W. R. (1996). "Foams in Enhanced Oil Recovery," in R. K. Prud'homme and S. Khan, ed., Foams: Theory, Measurements and Applications. Marcel Dekker, New York. 
Rossen, W. R., \& Boeije, C. S. (2015). Fitting Foam-Simulation-Model Parameters to Data: II. Surfactant-Alternating-Gas Foam Applications. Spe Reservoir Evaluation \& Engineering, 18(2), 273-283.

Rossen, W. R., \& Wang, M. W. (1999). Modeling Foams for Acid Diversion. SPE Journal, 4(2), 92-100. https://doi.org/10.2118/56396-PA

Schramm, L. L., \& Smith, D. H. (1996). Foams: Fundamentals and Applications in the Petroleum Industry. American Chemical Society (Vol. 10). American Chemical Society. https://doi.org/10.1021/ef950077m

Schulze-Schlarmann, J., Buchavzov, N., \& Stubenrauch, C. (2006). A disjoining pressure study of foam films stabilized by tetradecyl trimethyl ammonium bromide C14TAB. Soft Matter, 2(7), 584. https://doi.org/10.1039/b602975b

Simjoo, M., Dong, Y., Andrianov, A., Talanana, M., \& Zitha, P. (2012). Novel Insight into Foam Mobility Control. SPE Journal, (September), 1-15. https://doi.org/10.2523/15338MS

Simjoo, M., \& Zitha, P. (2013). Effects of Oil on Foam Generation and Propagation in Porous Media. In SPE Enhanced Oil Recovery Conference. Society of Petroleum Engineers. https://doi.org/10.2118/165271-MS

Simjoo, M., \& Zitha, P. L. J. (2015). Modeling of Foam Flow Using Stochastic Bubble Population Model and Experimental Validation. Transport in Porous Media, 799-820. https://doi.org/10.1007/s11242-015-0468-y

Stone, H. L. (1973). Estimation of Three-Phase Relative Permeability and Residual Oil Data. Journal of Canadian Petroleum Technology, 12(4), 53-61. https://doi.org/10.2118/7304-06

Tanzil, D., Hirasaki, G. J., \& Miller, C. A. (2002). Conditions for Foam Generation in Homogeneous Porous Media. In SPE/DOE Improved Oil Recovery Symposium. Society of Petroleum Engineers. https://doi.org/10.2118/75176-MS

$\mathrm{Xu}, \mathrm{Q}$., \& Rossen, W. R. (2003). Effective viscosity of foam in periodically constricted tubes. Colloids and Surfaces A: Physicochemical and Engineering Aspects, 216(1), 175-194. https://doi.org/10.1016/S0927-7757(02)00547-2 